\title{
Effect of extended photoperiod during winter on growth and onset of puberty in Murrah buffalo heifers
}

\author{
Ashwani Kumar Roy, Mahendra Singh, Parveen Kumar and B. S. Bharath Kumar
}

Division of Dairy Cattle Physiology, National Dairy Research Institute, Karnal, Haryana, India. Corresponding author: Ashwani Kumar Roy, e-mail: royashwani@gmail.com,

MS: chhokar.ms@gmail.com,PK: drpk1959@gmail.com, BSBK: bharath.kumar.vet@gmail.com

Received: 17-08-2015, Revised: 08-01-2016, Accepted: 16-01-2016, Published online: 27-02-2016

doi: 10.14202/vetworld.2016.216-221 How to cite this article: Roy AK, Singh M, Kumar P, Kumar BSB (2016) Effect of extended photoperiod during winter on growth and onset of puberty in Murrah buffalo heifers, Veterinary World, 9(2): 216-221.

\begin{abstract}
Aim: To investigate the effect of extended photoperiod on growth rate, hormonal levels, and puberty in Murrah heifers.

Materials and Methods: About 14 Murrah buffalo heifers were divided into normal day photoperiod (NDP; $\mathrm{n}=7$ ) and extended NDP (ENDP; $\mathrm{n}=7$ ) groups. The ENDP group was exposed to $4 \mathrm{~h}$ of extended photoperiod with artificial light (160 lux) after sunset for 3 months during winter.

Results: Group, age and group-by-age interaction effects on plasma glucose concentrations were non-significant $(p>0.05)$. A significant effect of age on non-esterified fatty acids $(p<0.05)$, cholesterol $(p<0.01)$, and triglycerides $(p<0.05)$ concentrations was observed. Group and group-by-age interaction effects on plasma $T_{3}, T_{4}$, leptin, $17 \beta$ estradiol, prolactin and melatonin concentrations were non-significant $(\mathrm{p}>0.05)$ while significant $(\mathrm{p}<0.05)$ age effect on $\mathrm{T}_{4}$, leptin and melatonin concentrations was observed. With respect to the circadian pattern of melatonin and prolactin, the group, time and groupby-time interaction effects were non-significant $(\mathrm{p}>0.05)$. Average daily gain and dry matter intake of heifers were nonsignificant between the NDP and ENDP groups but were comparatively higher in ENDP group. By the end of the experiment, 6 out of 7 heifers attained puberty in ENDP group in comparison to 4 out of 7 in NDP group.
\end{abstract}

Conclusion: Extending the photoperiod by artificial light for $4 \mathrm{~h}$ during winter season resulted in better growth rate and early onset of puberty in Murrah buffalo heifers.

Keywords: buffalo, leptin, melatonin, metabolites, photoperiod, prolactin, puberty.

\section{Introduction}

Buffaloes are the major source of milk production, and they contribute significantly to the economy of many countries in Southeast Asia [1]. More than $50 \%$ of the world population of 148 million buffaloes is reared in India. Late maturity, silent heat coupled with poor expression of estrus, irregular estrous cycle, seasonality in breeding, anoestrus, low conception rate, long postpartum interval, and repeat breeding are the well-known drawbacks leading to low productivity in this species [2-4]. Pubertal development involves physical, behavioral, and hormonal changes that are linked to the activation of the hypothalamic-adenohypophyseal-gonadal axis [5].

Management of photoperiod influences the attainment of puberty and prolactin secretion in beef heifers housed in an outdoor environment [6]. Onset of puberty in cattle is largely influenced by feed intake, quality of feed, and body weight (BW) gain [7]. Recent

Copyright: Roy, et al. Open Access. This article is distributed under the terms of the Creative Commons Attribution 4.0 International License (http://creativecommons.org/licenses/by/4.0/), which permits unrestricted use, distribution, and reproduction in any medium, provided you give appropriate credit to the original author(s) and the source, provide a link to the Creative Commons license, and indicate if changes were made. The Creative Commons Public Domain Dedication waiver (http://creativecommons.org/ publicdomain/zero/1.0/) applies to the data made available in this article, unless otherwise stated. research has demonstrated that feeding replacement heifers to traditional target BW increased development costs without improving reproduction or subsequent calf production relative to development systems in which heifers were developed to lighter target BW ranging from $50 \%$ to $57 \%$ of mature $\mathrm{BW}[8,9]$. Murrah buffaloes attain puberty between the ages of 33.1 and 36.5 months [10], whereas indigenous breeds such as Haryana, Kankrej and Sahiwal, reared under same management and environmental conditions, attain puberty at 24.6 months [11]. Feed efficiency improves by $9 \%$ in crossbred beef heifers by extending the photoperiod during winter [12]. Strong and clear estrous, increased progesterone, estradiol-17 $\beta$, and declined plasma melatonin in buffalo heifers exposed to $4 \mathrm{~h}$ of artificial light have been reported during autumn and winter seasons after sunset [13]. No significant changes in eating behavior, daily intake or live weight gain in buffalo heifers subjected to artificial light after sunset for $6 \mathrm{~h}$ have been found [14].

Although exposing the heifers to extended photoperiod seemed to be beneficial and economical, there are only a few investigations available in this regard indicating contradictory results. With this perspective, the present study was designed to investigate the effect of extended photoperiod on certain plasma hormones, metabolites, growth and onset of puberty in Murrah buffalo heifers during winter. 


\section{Materials and Methods}

\section{Ethical approval}

The experiment was duly approved by the Institutional Animal Ethical Committee.

\section{Location and methodology}

The experiment was conducted between the months of December and February at National Dairy Research Institute, Karnal, India, which is situated at an altitude of $250 \mathrm{~m}$ above mean sea level, latitude and longitude position being $29^{\circ} 42^{\prime \prime} \mathrm{N}$ and $79^{\circ} 54^{\prime \prime} \mathrm{E}$, respectively. 14 Murrah buffalo heifers were selected and divided into control $(n=7)$ and treatment $(n=7)$ groups. A control group of heifers were exposed to natural photoperiod of $10.5 \mathrm{~h}$. The treatment group heifers were exposed to $4 \mathrm{~h}$ of extended photoperiod with artificial light (160 Lux) after the sunset during the experimental period.

Daily feed intake and feed refusal of both the groups were recorded throughout the experiment. Dry matter intake (DMI) was calculated as the difference between feed intake and refusal. All the animals were reared under same management practices. BWs and blood samples were obtained from all the animals at fortnight intervals. To determine the circadian patterns of melatonin and prolactin hormones, blood samples were collected at an interval of $4 \mathrm{~h}$ over a period of 24-h. Immediately after collection, the samples were transported to the laboratory in an ice box, then centrifuged at $3000 \mathrm{rpm}$ for $15 \mathrm{~min}$ to obtain plasma which was in different aliquots and stored at $-20^{\circ} \mathrm{C}$ until analyzed for hormones and metabolites.

Plasma glucose was estimated by glucose oxidase-peroxidase method using commercial kits (Avecon Healthcare Pvt. Ltd.). Plasma cholesterol was estimated by cholesterol oxidase-phenol antipyrine (PAP) Trinder's method using commercial kits (Avecon Healthcare Pvt. Ltd.). Plasma triglycerides were estimated by glycerol phosphate oxidase-PAP Trinder's method using commercial kits (Avecon Healthcare Pvt. Ltd.). The copper soap solvent extraction method [15] was adopted for the estimation of plasma non-esterified fatty acids (NEFA). Progesterone (Cayman Chemical Company), estradiol-17 $\beta$, leptin, prolactin and melatonin (Cloudclone Corp.) concentrations were estimated by enzyme immunoassays kits. The intra- and inter-assay coefficients of variation were $<10 \%$ for all the hormones. Age at puberty was determined by behavioral signs, plasma progesterone levels [13] and ultrasound examination of the ovaries.

\section{Statistical analysis}

Mixed model ANOVA (repeated measures linear model) was conducted to compare the BWs, metabolites, and hormone concentrations between normal day photoperiod (NDP) and extended NDP (ENDP) groups across the time periods. With respect to the circadian pattern of melatonin and prolactin, group, time and group-by-time interaction effects were determined by using mixed model ANOVA. The mean differences in BW, metabolites and hormone concentrations between the NDP and ENDP groups at each fortnight were analyzed by Student's t-test. GraphPad Prism (Version 5) and SPSS (Version 16) software was used to perform the statistical analysis.

\section{Results and Discussion}

BWs (Figure-1) and DMI (Figure-2) of heifers did not differ significantly $(\mathrm{p}>0.05)$ between short day (NDP) and extended short day photoperiods (ENDP). The mean \pm standard error of mean (SEM) glucose concentrations in the short day (NDP) and extended short day photoperiod (ENDP) groups were 76.4 \pm 0.98 and $78.4 \pm 1.05 \mathrm{mg} / \mathrm{dl}$, respectively (Table-1). There were no effects of group, age and group-by-age interaction on plasma glucose concentrations. The mean NEFA concentrations in NDP and ENDP groups were $136 \pm 53.6$ and $168 \pm 54.6 \mathrm{mM} / \mathrm{L}$, respectively. A significant $(p<0.05)$ effect of age on NEFA concentrations

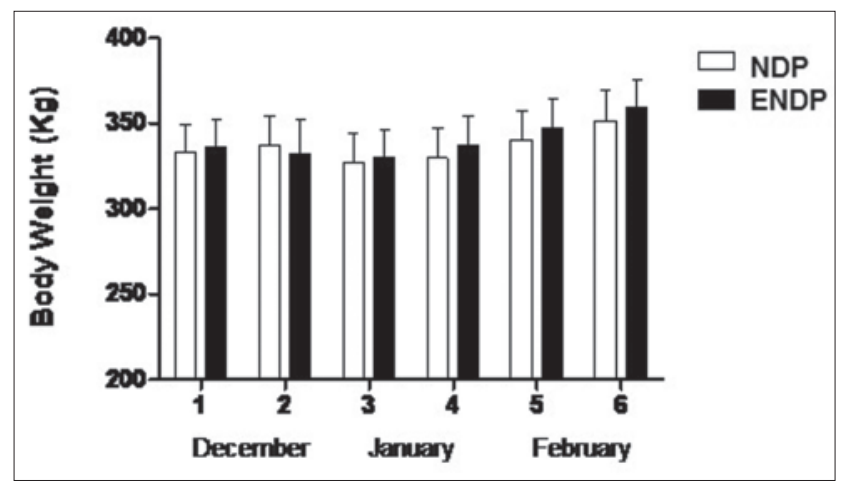

Figure-1: Mean ( \pm standard error) body weight values in normal day photoperiod (NDP) and extended NDP groups.

Table-1: Mean \pm SE values of different metabolites in NDP and ENDP groups during the experimental period.

\begin{tabular}{|c|c|c|c|c|c|c|c|c|}
\hline \multirow[t]{2}{*}{ Fortnight } & \multicolumn{2}{|c|}{ Glucose (mg/dl) } & \multicolumn{2}{|c|}{ NEFA $(\mu \mathrm{m} / \mathrm{L})$} & \multicolumn{2}{|c|}{ Cholesterol (mg/dl) } & \multicolumn{2}{|c|}{ Triglycerides $(\mathrm{mg} / \mathrm{dl})$} \\
\hline & NDP & ENDP & NDP & ENDP & NDP & ENDP & NDP & ENDP \\
\hline 1 & $77.2 \pm 1.54$ & $75.8 \pm 3.21$ & $40.0 \pm 16.2$ & $159 \pm 128$ & $101 \pm 7.19$ & $98.0 \pm 5.90$ & $91.0 \pm 4.21$ & $74.3 \pm 5.40$ \\
\hline 2 & $79.41 \pm 2.61$ & $80.67 \pm 2.97$ & $363 \pm 144$ & $413 \pm 111$ & $110 \pm 13.1$ & $108 \pm 6.97$ & $86.3 \pm 7.52$ & $84.7 \pm 10.1$ \\
\hline 3 & $77.26 \pm 2.33$ & $81.37 \pm 4.59$ & $158 \pm 66.7$ & $98.9 \pm 41.1$ & $101 \pm 5.94$ & $102 \pm 7.24$ & $78.6 \pm 8.77$ & $70.0 \pm 3.90$ \\
\hline 4 & $76.71 \pm 2.10$ & $76.17 \pm 2.63$ & $190 \pm 78.3$ & $132 \pm 47.9$ & $77.6 \pm 3.47$ & $88.9 \pm 5.28$ & $87.8 \pm 8.60$ & $97.5 \pm 5.11$ \\
\hline 5 & $75.39 \pm 1.60$ & $76.35 \pm 2.10$ & $40.3 \pm 18.84$ & $186 \pm 139$ & $79.7 \pm 6.25$ & $76.9 \pm 6.10$ & $83.8 \pm 4.67$ & $85.0 \pm 4.57$ \\
\hline 6 & $72.24 \pm 1.51$ & $80.20 \pm 2.20$ & $24.1 \pm 4.25$ & $18.0 \pm 8.64$ & $82.5 \pm 5.91$ & $87.5 \pm 12.5$ & $92.4 \pm 4.91$ & $81.0 \pm 3.84$ \\
\hline
\end{tabular}

$\mathrm{NDP}=$ Normal day photoperiod group, ENDP=Extended normal day photoperiod group, NEFA=Non-esterified fatty acids, $\mathrm{SE}=$ Standard error 


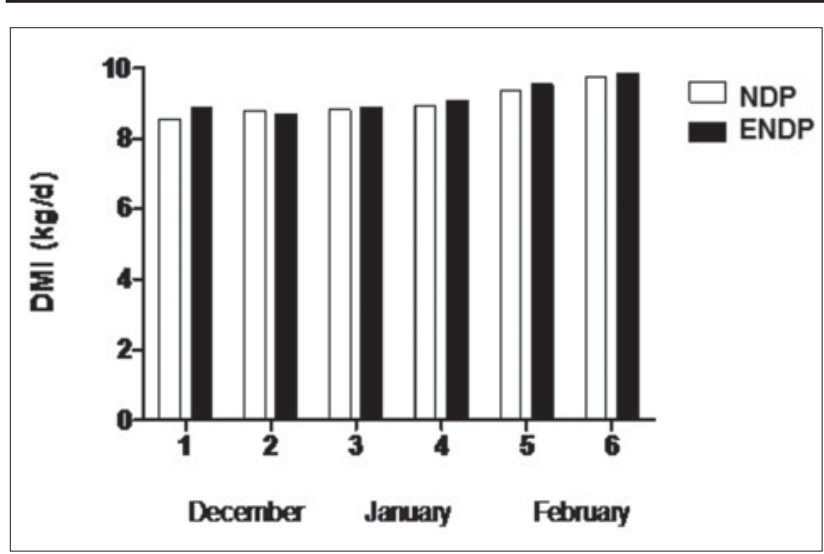

Figure-2: Mean ( \pm standard error) dry matter intake in normal day photoperiod (NDP) and extended NDP groups. was observed. A similar range of plasma glucose and NEFA was observed in Murrah buffaloes during winter [16]. The mean plasma cholesterol concentrations in NDP and ENDP groups were $92.3 \pm 5.75$ and $93.8 \pm 4.72 \mathrm{mg} / \mathrm{dl}$, respectively. There was significant $(p<0.01)$ effect of age on plasma cholesterol concentrations. Plasma triglycerides concentrations in NDP and ENDP groups were $86.7 \pm 2.05$ and $82.1 \pm 3.92 \mathrm{mg} / \mathrm{dl}$, respectively. Significant $(p<0.05)$ effect of age on triglycerides concentrations was observed.

The mean \pm SEM concentrations of plasma $T_{3}$, $\mathrm{T}_{4}$, leptin, $17 \beta$ estradiol, prolactin and melatonin in NDP group were $1.43 \pm 0.07 \mathrm{ng} / \mathrm{ml}, 46.0 \pm 2.05 \mathrm{ng} / \mathrm{ml}$, $413 \pm 56.4 \mathrm{pg} / \mathrm{ml}, 2.68 \pm 0.35 \mathrm{pg} / \mathrm{ml}, 14.1 \pm 2.11 \mathrm{ng} / \mathrm{ml}$
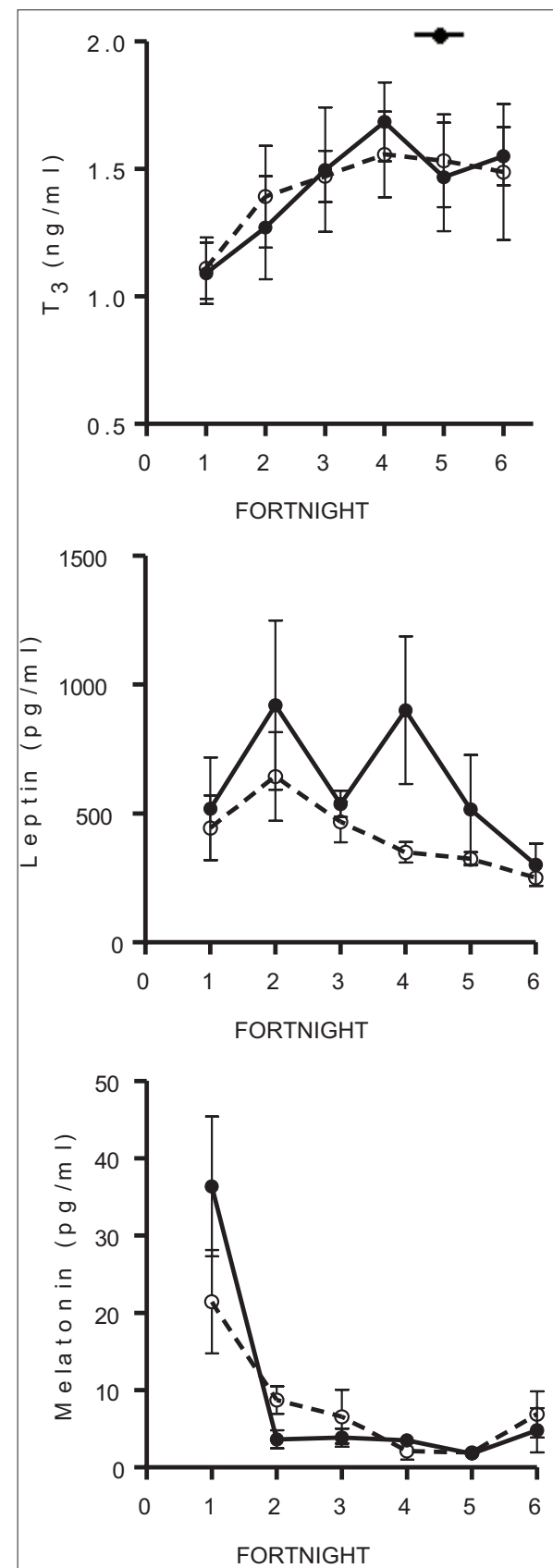
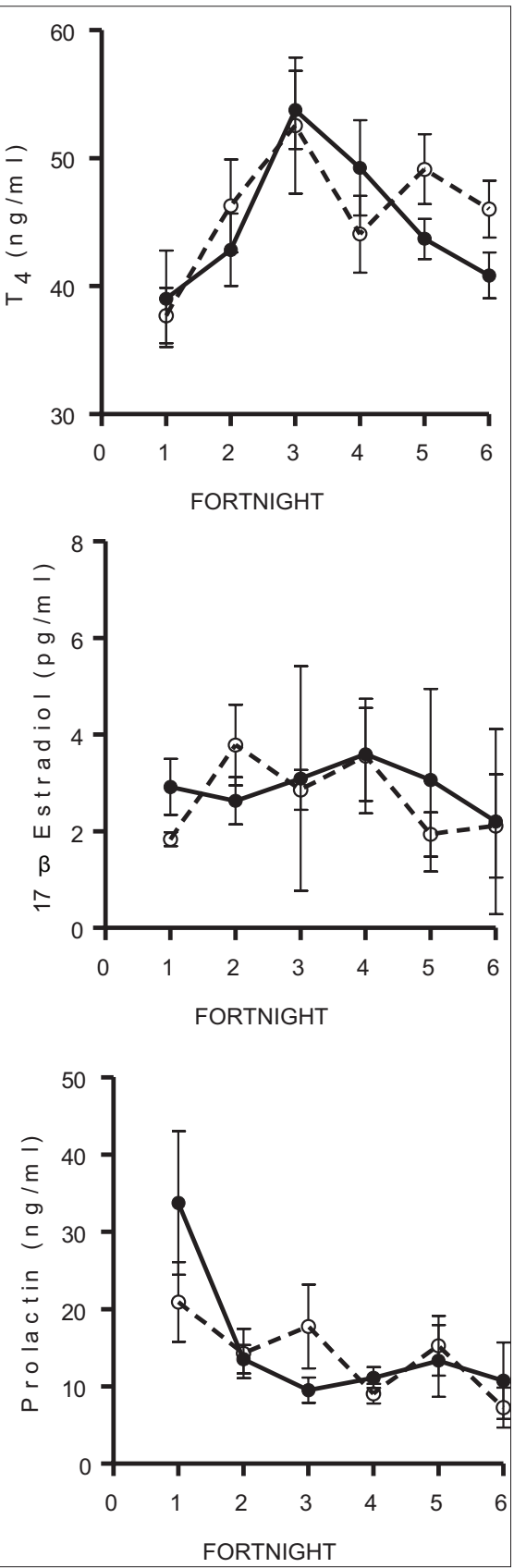

Figure-3: Mean ( \pm standard error) plasma concentrations of $\mathrm{T}_{3}, \mathrm{~T}_{4}$, leptin, $17 \beta$ estradiol, melatonin and prolactin in normal day and extended normal day photoperiod groups. 
and $7.95 \pm 2.92 \mathrm{pg} / \mathrm{ml}$, respectively (Figure-3). Plasma $\mathrm{T}_{3}, \mathrm{~T}_{4}$, leptin, $17 \beta$ estradiol, prolactin and melatonin in ENDP group were $1.43 \pm 0.09 \mathrm{ng} / \mathrm{ml}, 44.9 \pm 2.27 \mathrm{ng} / \mathrm{ml}$, $616 \pm 99.7 \mathrm{pg} / \mathrm{ml}, 2.92 \pm 0.19 \mathrm{pg} / \mathrm{ml}, 15.4 \pm 3.74 \mathrm{ng} / \mathrm{ml}$, and $9.00 \pm 5.49 \mathrm{pg} / \mathrm{ml}$, respectively. Group and groupby-age interaction effects on all the hormone concentrations were non-significant $(p>0.05)$. Significant $(\mathrm{p}<0.05)$ age effect on plasma $\mathrm{T}_{4}$, leptin and melatonin concentrations was observed. The plasma $\mathrm{T}_{3}$ and $\mathrm{T}_{4}$ levels observed in this experiment was in accordance with a similar study conducted on peripubertal Murrah buffaloes [17]. The lower plasma $17 \beta$ estradiol concentrations $(<5 \mathrm{pg} / \mathrm{ml})$ observed in both the groups of this study was also in accordance with the results obtained [18]. By the end of the experiment, 6 out of 7 heifers attained puberty in ENDP group, whereas only 4 out of 7 heifers attained puberty in NDP group. Attainment of puberty was determined by behavioral signs, and confirmed by both plasma progesterone levels $(>1 \mathrm{ng} / \mathrm{ml})$ and presence of corpus luteum through ultrasound examination of ovaries.

The circadian pattern of melatonin and prolactin in both NDP and ENDP groups are depicted in Figure-4. There were no group, time and

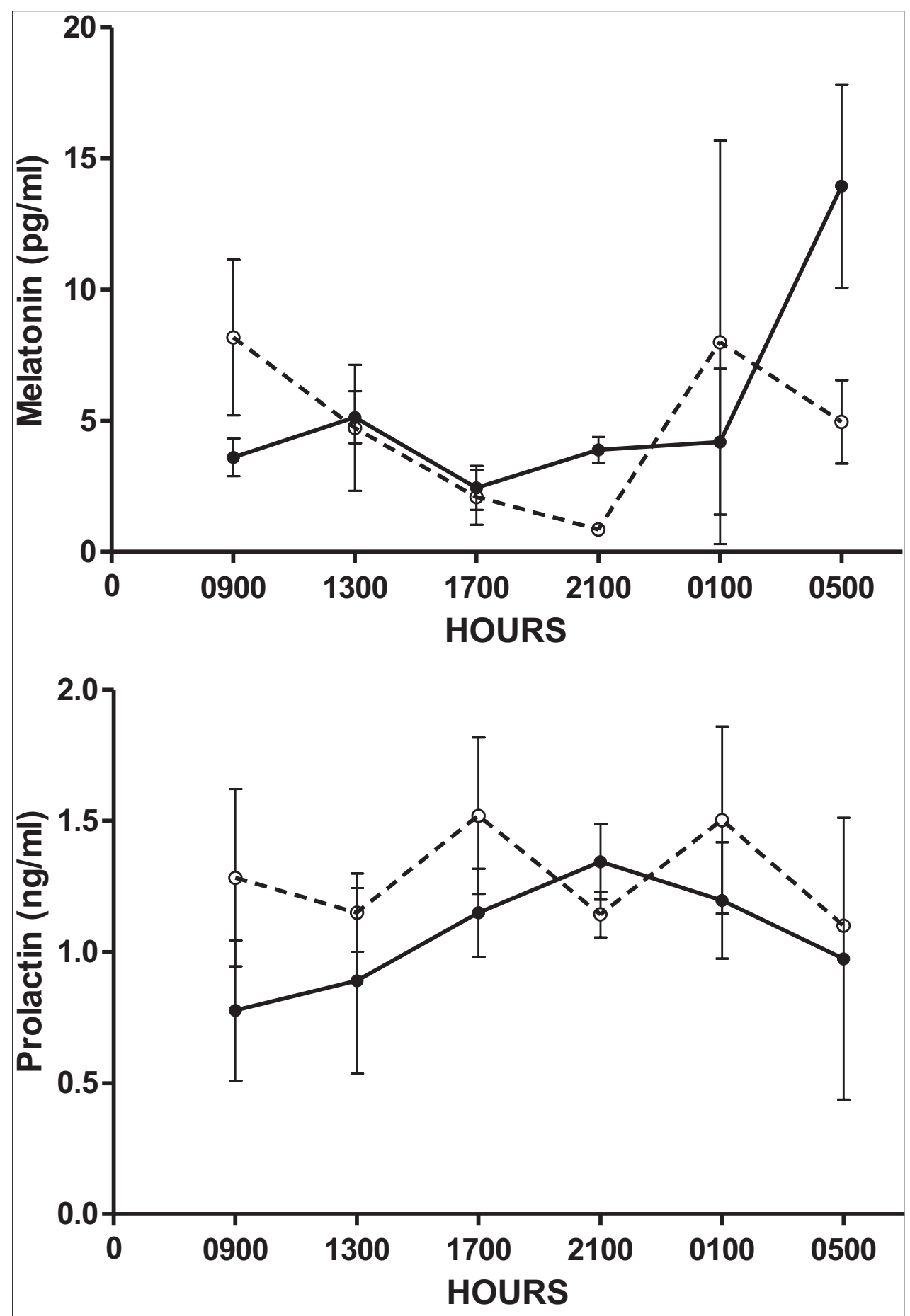

Figure-4: Circadian trend of prolactin and melatonin in normal day and extended normal day photoperiod groups. 
group-by-time interaction effects on both plasma melatonin and prolactin concentrations. Each heifer, irrespective of their group, showed different levels and pattern of melatonin and prolactin release. The plasma melatonin concentrations in NDP and ENDP groups ranged between $0.82-23.4$ and $1.16-20.7 \mathrm{pg} / \mathrm{ml}$, respectively. Plasma prolactin concentrations in NDP and ENDP groups ranged between 0.97-2.19 and $0.35-1.87 \mathrm{ng} / \mathrm{ml}$, respectively. There was a definite circadian trend of plasma melatonin in buffaloes reared in few farms of Italy [19]. However, the buffaloes reared in a certain farm did not show a definite circadian pattern. The different trends of melatonin could be attributed to selection process practiced in the farms and targeted elimination of seasonal buffaloes [20]. The genetic selection criteria implemented to maintain the breeding herd in our farm reasons for the different pattern of melatonin release, irrespective of group.

In the present study, the DMI and BWs of NDP and ENDP groups did not differ significantly $(p>0.05)$. However, the higher average daily gain was observed among the heifers of ENDP as compared to NDP group. Exposure of experimental group to $4 \mathrm{~h}$ of extended photoperiod with artificial light (160 Lux) after sunset may have increased their feed efficiency ratio and thus higher average daily gain. An increase in feed efficiency by extending photoperiod during winter in crossbred beef heifers corroborates the result of this study [21]. They also observed a non-significant difference in DMI between the natural and extended photoperiod groups, which agreed with our results. Plasma leptin appears to be an important link between metabolic status, the neuroendocrine axis and subsequent fertility in farm animals [21-23]. It also serves as a metabolic signal that acts on the hypothalamic-pituitary-ovarian axis to enhance gonadotropin-releasing hormone and luteinizing hormone secretion and ovarian function [24,25]. Proper management practices, nutrition, and optimum climatic conditions are indispensable for homeostasis and optimum productivity in cattle [26]. In the present study, the mean plasma leptin concentrations were comparatively higher in the ENDP $(616 \pm 99.7 \mathrm{pg} / \mathrm{ml})$ group than in NDP $(413 \pm 56.4 \mathrm{pg} / \mathrm{ml})$ group. An improved feed efficiency and better average daily gain in ENDP group may have influenced the plasma leptin concentrations and further attainment of puberty.

\section{Conclusion}

Extending the natural photoperiod by artificial light (160 Lux) for $4 \mathrm{~h}$ daily during winter season resulted in better growth rate and early onset of puberty in Murrah buffalo heifers.

\section{Authors' Contributions}

AKR: Planning and execution of experiment. Drafted and revised the manuscript; MS: Hormone assays; PK: Management of animals in the farm;
BSBK: Statistical analysis of data. All authors read and approved the final manuscript.

\section{Acknowledgments}

Financial support provided by the Director, National Dairy Research Institute, India and the National Initiative on Climate Resilience in Agriculture, India are greatly acknowledged.

\section{Competing Interests}

The authors declare that they have no competing interests.

\section{References}

1. Mirmahmoudi, R. and Prakash, B.S. (2012) The endocrine changes, the timing of ovulation and the efficacy of the doublesynch protocol in the murrah buffalo (Bubalus bubalis). Gen. Comp. Endocrinol., 177(1): 153-159.

2. Terzano, G.M., Lucia, B.V. and Antonio, B. (2012) Overview on reproductive endocrine aspects in buffalo. J. Buffalo Sci., 1: 126-138.

3. Perera, B.M.A. (2011) Reproductive cycles of buffalo. Anim. Reprod. Sci., 124(3), 194-199.

4. Mirmahmoudi, R., Souri, M. and Prakash, B.S. (2014) Comparison of endocrine changes, timing of ovulations, ovarian follicular growth, and efficacy associated with estradoublesynch and heat synch protocols in Murrah buffalo cows (Bubalus bubalis). Theriogenology, 82(7): 1012-1020.

5. Sisk, C.L. and Foster, D.L. (2004) The neural basis of puberty and adolescence. Nat. Neurosci., 7: 1040-1047.

6. Small, J.A., Glover, N.D., Kennedy, A.D., McCaughey, W. P. and Ward, D.R. (2003) Photoperiod effects on the development of beef heifers. Can. J. Anim. Sci., 83: 721-730.

7. Brito, L.F.C., Barth, A.D., Rawlings, N.C., Wilde, R.E., Crews, D.H., Boisclair, Y.R. and Kastelic, J.P. (2007) Effect of feed restriction during calf-hood on serum concentrations of metabolic hormones, gonadotropins, testosterone, and on sexual development in bulls. Reproduction, 134(1): 171-181.

8. Davis Rincker, L.E., Vandehaar, M.J., Wolf, C.A., Liesman, J.S., Chapin, L.T. and Weber Nielsen, M.S. (2011) Effect of intensified feeding of heifer calves on growth, pubertal age, calving age, milk yield, and economics. J. Dairy Sci., 94: 3554-3567.

9. Funston, R.N., Martin, J.L., Larson, D.M. and Roberts, A.J. (2012) Physiology and endocrinology symposium: Nutritional aspects of developing replacement heifers. J. Anim. Sci., 90: 1166-1171.

10. Saini, M.S., Dhanda, O.P., Singh, N. and Georgie, G.C. (1998) The effect of improved management on the reproductive performance of pubertal buffalo heifers during the summer. Indian J. Dairy Sci., 51(4): 250-253.

11. Jamara, M.S., Mehla, R.K., Singh, M., Ali, M.M. and Chouhan, N. (2014) Effect of the feed Shatavari (Asparagus racemosus) on body weight and puberty of Sahiwal heifers. Int. J. Agric. Sci. Vet. Med., 2(1): 64-67.

12. Kennedy, A.D., Bergen, R.D., Lawson, T.J., Small, J.A. and Veira, D.M. (2004) Effects of evening feeding and extended photoperiod on growth, feed efficiency, live animal carcass traits and plasma prolactin of beef heifers housed outdoors during two Manitoba winters. Can. J. Anim. Sci. 84: 491-500.

13. Kassim, N.S.I., Afify, A.A. and Hassan, H.Z. (2008) Effect of photoperiod length on some reproductive traits and hormonal profiles in buffalo heifers. Am. Euras. J. Agric. Environ. Sci., 3(4): 646-655.

14. Somparn, P., Gibb, M.J., Markvichitr, K., Chaiyabutr, N., Thummabood, S. and Vajrabukka, C. (2007) Effect of 
supplementary lighting on eating behaviour by corralled swamp buffalo (Bubalus bubalis) heifers in Thailand. Songklanakarin J. Sci. Technol., 29(2): 399-411.

15. Shipe, W.F., Senyk, G.F. and Fountain, K.B. (1980) Modified copper soap solvent extraction method for measuring free fatty acids in milk. J. Dairy Sci. 63: 193-198.

16. Khan, H.M., Mohanty, T.K., Bhakat, M., Raina, V.S. and Gupta, A.K. (2011) Relationship of blood metabolites with reproductive parameters during various seasons in Murrah buffaloes. Asian Australas. J. Anim. Sci., 24(9): 1192-1198.

17. Ingole, S.D., Deshmukh, B.T., Nagvekar, A.S. and Bharucha, S.V. (2012) Serum profile of thyroid hormones from birth to puberty in buffalo calves and heifers. $J$. Buffalo Sci., 1(1): 39-49.

18. Mondal, S., Prakash, B.S. and Palta, P. (2007) Endocrine aspects of oestrous cycle in buffaloes (Bubalus bubalis): An overview. Asian-Aust. J. Anim. Sci., 20(1): 124-131.

19. Parmeggiani, A., Di Palo, R. and Zicarelli, L. (1994) Melatonin and reproductive seasonality of the Della Buffalo, Agri. Res. 16: 41-8.

20. Seren, E., Parmeggiani, A., Campanile, G. (1995) The control of ovulation in Italian buffalo. In: Enne, G., Greppi, G.F. and Lauria, A., editors. Reproduction and Animal Breeding Advances and Strategy. Elsevier, Amsterdam. p265-275.
21. Barb, C.R. and Kraeling, R.R. (2004) Role of leptin in the regulation of gonadotropin secretion in farm animals. Anim. Reprod. Sci., 82: 155-167.

22. Lomniczi, A., Wright, H. and Ojeda, S.R. (2015) Epigenetic regulation of female puberty. Front. Neuroendocrinol., 36: $90-107$

23. Vázquez, M.J., Romero-Ruiz, A. and Tena-Sempere, M. (2015) Roles of leptin in reproduction, pregnancy and polycystic ovary syndrome: Consensus knowledge and recent developments. Metabolism, 64(1): 79-91.

24. Campbell, B.K., Guitierrez, C.G., Armstrong, D.G., Webb, R. and Baird, D.T. (2000) Leptin: In vitro and in vivo evidence for direct effects on the ovary in monovulatory ruminants. Hum. Reprod., 14: 15-16.

25. Takumi, K., Shimada, K., Iijima, N. and Ozawa, H. (2015) Maternal high-fat diet during lactation increases Kiss 1 mRNA expression in the arcuate nucleus at weaning and advances puberty onset in female rats. Neurosci. Res., 100: 21-28.

26. Bova, T.L., Chiavaccini, L., Cline, G.F., Hart, C.G., Matheny, K., Muth, A.M., Voelz, B.E., Kesler, D. and Memili, E. (2014) Environmental stressors influencing hormones and systems physiology in cattle. Reprod. Biol. Endocrinol., 12: 58.

\section{$* * * * * * * *$}

